\title{
High genetic diversity in arbuscular mycorrhizal fungi: evidence for recombination events
}

\author{
P. VANDENKOORNHUYSE $\dagger^{*}$, C. LEYVAL $\uparrow \& I$. BONNIN $†$ \\ $\dagger$ Centre de Pédologie Biologique, CNRS UPR 6831, 17 rue Notre-Dame des Pauvres, BP5, F-54501 Vandoeuvre les \\ Nancy cedex, $¥$ Laboratoire de Génétique et Evolution des Populations Végétales, UPRESA CNRS 8016, \\ Université de Lille 1, Bât. SN2, F-59655 Villeneuve d'Ascq cedex, France
}

The genetic diversity of spores of two indigenous species of Glomus isolated from three soils of a longterm field experiment amended by different quantities of sewage sludges has been evaluated. Three populations of spores of Glomus claroideum (W2537) and three populations of spores of Glomus DAOM 225952 (W2538) were analysed using a microsatellite primer and aliquots of genomic DNA were obtained from single spores (Inter Simple Sequence Repeat (ISSR) fingerprints). 39 polymorphic bands were found for G. claroideum, and 43 in Glomus DAOM 225952. The intraspecific diversity was high, ranging from 22 to 33 different electrophoretic types for G. claroideum, and 15-27 for Glomus DAOM 225952 depending on the population. Resampling experiments showed that the number of polymorphic bands was sufficient to score all multilocus profiles in the populations and to describe the clonality structure within populations. On average, one multilocus profile was represented by about four spores whatever the population and the species. Partitioning of the within-species phenotypic variance showed that more than $92 \%$ of the variation was found within populations, while the among-population variance component accounted for less than $8 \%$, even though it was statistically different from 0 . This result is confirmed by the fact that only few multilocus profiles were shared by two populations of G. claroideum, and none by populations of Glomus DAOM 225952. In addition to the high level of diversity observed within populations, linkage disequilibria analyses and association indices calculated across loci indicates that reproduction cannot be solely clonal. Recombination or recombination-like events are likely to occur in these arbuscular mycorrhizal fungi. An 'epidemic' population structure was found for both fungal species in the soil that had received high amounts of sewage sludge.

Keywords: arbuscular mycorrhizal (AM) fungi, clonality, genetic variation, ISSR fingerprints, recombination.

\section{Introduction}

Arbuscular mycorrhizal (AM) fungi in Glomales, zygomycetes (Morton \& Benny, 1990), are an important group of rhizospheric microorganisms forming symbioses with most terrestrial plants. These fungi are of major importance in the establishment and maintenance of terrestrial plant ecosystems (Pirozynski \& Malloch, 1975; Fitter \& Moyersoen, 1996; Selosse \& Le Tacon, 1998) and may determine plant community structure (Streitwolf-Engel et al., 1997; van der Heijden et al.,

\footnotetext{
*Correspondence and present address: University of York, Department of Biology, PO Box 373, York YO10 5YW, U.K. E-mail: psjv1@york.ac.uk/p.vandenkoornhuyse@free.fr
}

1998a; 1998b). As a consequence, an alteration of the AM fungal diversity should modify the rhizospheric potentialities and ultimately the soil fertility. Nevertheless, little is known about the diversity of AM fungi in soils, especially the genetic diversity and its spatial structure. This dearth results from the strict biotrophy of AM fungi, to the difficulties in obtaining sufficient fungal material, and to the lack of knowledge of the reproductive system and the mutation rate. Moreover, AM spores seem to contain high numbers of nuclei (Biancotto \& Bonfante, 1993) and intrasporal variations between nuclei have been suggested for Gigaspora margarita (Lanfranco et al., 1999), possibly because of hyphal anastomosis (Giovannetti et al., 1999), which do not imply caryogamy or meiosis (Hosny et al., 1999). 
In order to study population diversity of AM fungi, DNA markers based on the polymerase chain reaction are promising tools as they require very small amounts of DNA. Recently, highly variable minisatellites (Gadkar et al., 1997; Zézé et al., 1997) and amplified fragment length polymorphism (Rosendahl \& Taylor, 1997) revealed high genetic variation in AM fungi at both interspecific and intraspecific levels. Rosendahl \& Taylor (1997) did not find any evidence of recombination in Glomus caledonium and Glomus mosseae, suggesting that they reproduce clonally, although in the fungal kingdom, many species alternate sexual and asexual reproduction (Anderson et al., 1992). For example, the sexual fraction of populations of Puccinia graminis (Burdon \& Roelfs, 1985), and Erisiphe graminis (Brown \& Wolfe, 1990) has been easily recognized. It is more difficult to measure the contribution of asexual and sexual reproduction for fungi that do not have a recognized sexual stage. When genetic markers are available, one way to estimate the degree of clonality is to estimate the level of within-population linkage disequilibrium. The frequent recovery of one or a few multilocus genotypes in a population is usually taken as evidence of clonality. However, this does not permit exclusion of the hypothesis that these 'fitter' genotypes are initially obtained by recombination, increasing later in frequency by clonality ('epidemic structure' in Maynard Smith et al., 1993). Several factors, such as population structure, epistatic fitness interactions between loci, and genetic drift can cause linkage disequilibrium, even in populations in which recombination is frequent. Whereas the existence of linkage disequilibrium does not allow us to easily distinguish among these different processes, the presence of linkage equilibrium (the random association of alleles between loci) clearly indicates recombination. Different studies using genetic markers have shown that the reproductive system ranges from highly outcrossing in Cryphonectria parasitica (Milgroom et al., 1992) and in Mycosphaerella graminicola (Chen \& McDonald, 1996) to clonal in Sclerotinia sclerotiorum (Kohli et al., 1995). According to Chen \& McDonald (1996), in plant fungal pathogens, a high level of recombination provides an advantage in generating rapidly a lot of new combinations of virulence genes that match corresponding resistance genes in the host. More generally, in changing environments, recombination could allow more rapid adaptation (Butlin et al., 1999; Nürnberger et al., 1999; West et al., 1999).

The goal of the present study is to assess the genetic structure and the level of recombination in two AM fungi species, Glomus DAOM 225952 and Glomus claroideum (living in different ecological conditions) using ISSR (Inter Simple Sequence Repeat) fingerprinting (Zietkiewicz et al., 1994; Nagaoka \& Ogihara, 1997;
Esselman et al., 1999). This dominant PCR DNA marker allows DNA amplification between microsatellite regions. It seems to show a higher level of polymorphism and reproducibility than do RAPD markers (Nagaoka \& Ogihara, 1997; Esselman et al., 1999). Moreover, it has been used successfully to analyse polymorphism at the species level in different fungi (e.g. Buscot et al., 1996; Zhou et al., 1999). As the populations studied were sampled in three plots of a sewage sludge amendment field, showing different levels of pollution, we might expect that the level of recombination would increase with the level of environmental stress (i.e. the degree of soil pollution). Using a multilocus approach, results of genetic variability within and between populations (plots) are discussed in connection with the likelihood of recombination events in these species.

\section{Materials and methods}

\section{Soil and $A M$ spore sampling}

A long-term field experiment on an old arable soil in Braunschweig (FAL, Germany) was divided into plots, which received different treatments from 1980 to 1990. Crop rotation has been identical for all the plots for a number of decades. Three plots were sampled:

(i) plot 1 received only inorganic fertilisers $(180 \mathrm{kgN}$ $\mathrm{ha}^{-1} \mathrm{yr}^{-1}$ );

(ii) plot 2 was amended with $100 \mathrm{~m}^{3} \mathrm{ha}^{-1} \mathrm{yr}^{-1}$ of sewage sludge from a local works (equivalent to $4 \mathrm{t} \mathrm{ha}^{-1}$ of dry solid), and located at $21 \mathrm{~m}$ from plot 1 ;

(iii) plot 3 was amended with $300 \mathrm{~m}^{3} \mathrm{ha}^{-1} \mathrm{yr}^{-1}$ of the same local sewage sludge ( $12 \mathrm{t} \mathrm{ha}^{-1}$ dry solid). This plot is located $2 \mathrm{~m}$ from plot 2 and $19 \mathrm{~m}$ from plot 1 .

In order to limit the obvious danger of overlooking differences in diversity, the resolution of the sampling must be sufficient and representative of the studied area (Giller et al., 1997). Therefore, a sample of soil from the plough layer $(0-20 \mathrm{~cm})$ assumed to be large enough $\left(0.03 \mathrm{~m}^{3}\right)$ was taken from each plot in October 1994 as described in Knight et al. (1998). Physical and chemical soil properties were characterized as well as total and available heavy metal concentrations (Knight et al., 1998). The AM spore number in the three soils was very low (16, 18 and 3 healthy spores in $100 \mathrm{~g}$ of dry soil for plots 1, 2 and 3, respectively). Trap cultures with Allium porrum L. were made for each soil (Vandenkoornhuyse, 1998). Pots were cultivated in a growth chamber at $24 /$ $20{ }^{\circ} \mathrm{C}$ day/night temperature, $16 \mathrm{~h}$ per day, $70 \%$ relative humidity, $300 \mu \mathrm{M} \mathrm{s}^{-1} \mathrm{~m}^{-2}$ PAR and were harvested after 3 months. Pots were air-dried, roots were cut into small fragments and thoroughly mixed with the substrate (Vandenkoornhuyse, 1998). After trap cultures, the 
number of AM spores had significantly increased by up to 50 times (Vandenkoornhuyse, 1998). Glomus DAOM 225952 (voucher accession number W2538, registration number DAOM 225952) and Glomus claroideum (voucher accession number W2537) spores were identified morphologically (Vandenkoornhuyse, 1998). Populations 1, 2 and 3 of spores of G. claroideum and Glomus DAOM 225952 were isolated from the trap cultures on plots 1,2 and 3 , respectively.

\section{PCR and electrophoresis}

Spores were disinfected in Triton X100, Chloramine T and antibiotic solutions, as described previously Vandenkoornhuyse \& Leyval (1998). To confirm morphological identification, the SSU rDNA of one spore of each species was sequenced according Vandenkoornhuyse \& Leyval (1998) (GenBank accession numbers AF139733 and AF139732 for Glomus DAOM 225952 and G. claroideum, respectively) and every other spore was compared to the reference sequence by performing SSU rDNA RFLPs as follows. A 1350-bp DNA fragment of the SSU rDNA was amplified using the primer set $\mathrm{MH} 2 \mathrm{MH} 4$ (non-AM fungal specific), namely $5^{\prime}$ TTC GAT GGT AGG ATA GAG G3' and 5'GTC TCA CTA AGC CAT TC3', using an aliquot from a single disinfected crushed spore without DNA extraction (Vandenkoornhuyse \& Leyval, 1998). The PCR reaction and cycling regime were performed as described in Vandenkoornhuyse \& Leyval (1998). RFLPs of the amplified DNA fragment were studied using $15 \mu \mathrm{L}$ of PCR products directly digested with $4 \mathrm{U}$ of AseI, BanI, FokI (New England Biolabs), HinfI, and TaqI (Gibco BRL Life Technologies) restriction enzymes. According to the sequences of the SSU rDNA of Glomales available in GenBank, these five digestions correspond to a minimum of 56 polymorphic sites.

ISSR fingerprints were obtained using PCR with $(\mathrm{GTG})_{5}$ as primer. Amplifications were performed as described in Vandenkoornhuyse \& Leyval (1998). A quarter of the total spore DNA was used as template (the DNA of a single spore was used to perform both the SSU rDNA and the ISSR fingerprinting). Amplification products of the genomic fingerprints were separated on a $1.5 \%$ agarose (Eurobio) gel in $0.5 \times \mathrm{TAE}$ buffer, followed by ethidium bromide staining, and visualized under UV light. Electrophoreses were stopped after $18 \mathrm{~cm}$ of migration for a 100-bp DNA fragment. Molecular weights were estimated by reference to a 100-bp and 1-kbp DNA ladder (Gibco-BRL Life Technologies, Cergy-Pontoise, France).

In order to check for reproducibility, amplifications were repeated at least twice for each electrophoretic type, using the last quarter of a single spore DNA. No differences were found among fingerprinting replicates, even with different gel qualities or concentrations. In addition, to check that amplified fragments of identical mobility are homologous within species, digestions of the amplification products were performed using $15 \mu \mathrm{L}$ of PCR products and 4 units of TaqI (Gibco BRL Life Technologies). All the multilocus profiles which were represented by more than one spore were digested. Bands of identical mobility in different haplotypes are assumed to be identical. For each band, the total size of all digested fragments was equal to the size of the band, and no differences were observed among the digestion patterns of two identical bands generated with two different spores and/or haplotypes.

\section{Data analysis}

Data scoring. Using SSU rDNA PCR-RFLPs, the spores which presented an unknown restriction profile in comparison with the G. claroideum or Glomus DAOM 225952 expected profiles, were excluded from the analyses because these spores were probably misclassified (in the worst case, they represented $5 \%$ of spores isolated).

According to ISSR fingerprints, no multilocus profile was shared by Glomus DAOM 225952 and G. claroideum. Data analyses were performed separately for each species. For each polymorphic amplification product or polymorphic band (locus), there were two possible states (alleles), amplified fragment present (1), or absent (0). Multilocus profiles are hereafter referred to haplotypes.

Population structure. Clonal diversity within populations was measured by the complement of the Simpson index corrected for finite samples, $D$ (Pielou, 1969; Peet, 1974):

$D=1 \quad\left[\sum n_{i}\left(\begin{array}{ll}n_{i} & 1\end{array}\right) / N\left(\begin{array}{ll}N & 1\end{array}\right)\right]$

where $n_{i}$ is the number of samples of genotype $i$ and $N$ is the total number of samples. $D$ ranges from zero in a population composed of a single clone to one in a population where every individual sampled has a different genotype.

For each species, Analysis $O$ f Molecular Variance (AMOVA) (Excoffier et al., 1992) was used to estimate variance components for the electrophoretic types, partitioning the total genetic variation into that occurring within and among populations. AMOVA gives conventional estimations of $F_{\mathrm{ST}}$, by using an analysis of variance, according to Weir \& Cockerham (1984) and Weir (1990). In the present study, only haplotypic frequency information was used, and molecular 
information, such as the number of differences between haplotypes for example, was not taken into account. The significance levels of variance component estimates were computed by nonparametric permutational procedures of genotypes among populations. Analyses were performed using AMOVA v.1.55.

In order to test for the reproductive mode (i.e. clonal or recombining), the proportions of significant linkage disequilibria among pairs of fragments, and the Indices of Association (Maynard Smith et al., 1993) were estimated for each species within populations. In highly selfing and clonal species, high within-population levels of linkage disequilibria are expected. For each pair of loci, and each population, linkage disequilibria were tested by Fisher exact tests using GENEPOP v.3.1 (Raymond \& Rousset, 1995). Because multiple tests of significance were conducted (between 500 and 800 tests depending on the population), which could give significant disequilibria arising by chance only, Bonferroni's sequential procedure (Holm, 1979) was used, as suggested by Sokal \& Rohlf (1995). Tablewide significance levels were calculated in order to set an upper bound on familywise error rate (Rice, 1989).

The Index of Association (Maynard Smith et al., 1993) tests for association among loci by calculating the variance of similarities for all pairwise combinations of multilocus profiles. The variance for the observed data set is thus compared to that expected for data derived from a recombining population. Higher variances, or Indices of Association, are expected for clonal populations than for recombining ones. Indices of Association were estimated for each population using software developed by A. Burt (Burt et al., 1996). Significance is determined by the proportion of indices for 300 recombined datasets (artificially obtained by allele resampling within populations) that are identical or larger than the indices for the observed data. If the statistics for the observed dataset and for the recombined one are indistinguishable, the hypothesis of recombination cannot be rejected.

According to Maynard Smith et al. (1993), significant associations between loci may arise in a freely recombining population only because of the recent and explosive increase of particular multilocus genotypes in the population. When this effect is eliminated, the population should be panmictic. This is the reason why analyses of loci associations were performed on a dataset containing one spore per electrophoretic type only (putative clones removed).

\section{Results}

For Glomus claroideum, no highly frequent band $(>0.90)$ was detected and 4 out of the 39 polymorphic bands were rare $(<0.10)$ (Fig. 1). Out of the 43 polymorphic loci found for the Glomus DAOM 225952 species, no highly frequent band $(>0.90)$ was observed, and 6 bands were rare $(<0.10)$. Most of the band frequencies were different among populations (data not shown) and comprised between 0.10 and 0.70 (Fig. 1). Only 3 out of 39 bands were amplified in only a single population of $G$. claroideum: 1 in population 1 at the frequency of 0.12 , and 2 in population 3 at the frequency of 0.05 (data not shown). For Glomus DAOM 225952, 2 out of 43 bands were population specific: 1 in population 1 and 1 in population 3 at frequencies of 0.15 and 0.07 , respectively (data not shown).

Overall, 82 different electrophoretic types were detected among $330 \mathrm{G}$. claroideum spores, and 62 among 247 spores of Glomus DAOM 225952. On average, each multilocus profile was represented by four spores. Nevertheless, the number of spores having the same electrophoretic profile within a population was highly heterogeneous, ranging from 1 to 20 in G. claroideum, and 1 to 18 in Glomus DAOM 225952 (Fig. 2). According to Bonnin et al. (1996), the adequacy of the number of loci can be checked by analysing the influence of the number of loci on the number of electrophoretic types found per population. For each population, the number of electrophoretic types was quantified for 10 random combinations of 1-40 loci for Glomus DAOM 225952 (out of 43 fragments), and 1-39 for G. claroideum (out of 39 fragments). The six curves were asymptotic (Fig. 3). The number of electrophoretic types observed for each population increased with the number of loci sampled until a plateau was reached. A stable number of electrophoretic profiles was reached with 20-35 loci for both species (Fig. 3) showing that the 39 loci scored for $G$. claroideum and the 43 loci scored for Glomus DAOM 225952 were sufficient to describe the within-population clonal structure (Fig. 3).

The ratio of the number of electrophoretic types to the number of spores varied between 0.22 and 0.28 for both species (Table 1). Clonal diversity within populations, estimated by the corrected Simpson index, was high for both species $(0.925,0.931$, and 0.902 in population 1, 2, and 3 of Glomus DAOM 225952 and $0.959,0.930$, and 0.935 in population 1,2 , and 3 of G. claroideum).

No electrophoretic type was common to two populations of Glomus DAOM 225952, and no more than two types to two populations of G. claroideum (Fig. 2). Most of the variation in the multilocus profiles resulted from differences among spores within populations ( $92 \%$ and $94 \%$, respectively, for Glomus DAOM 225952 and G. claroideum). Only $8 \%$ and $6 \%$ of the variation was found among populations (Table 2), but the differentiation at this level was highly significant $(P<0.001)$. 
Glomus claroideum W2537
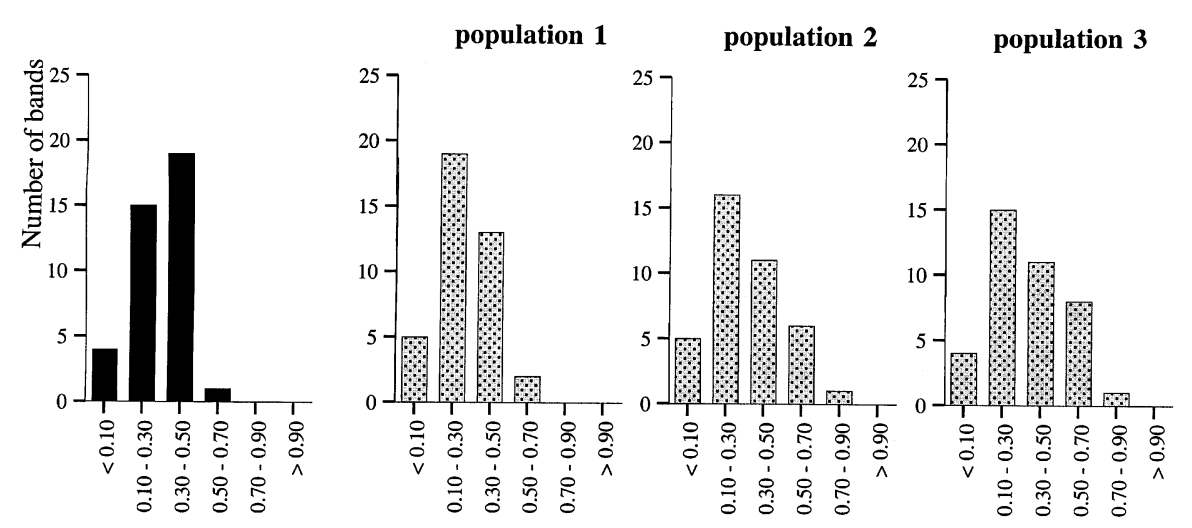

Frequency

\section{Glomus DAOM 225952}
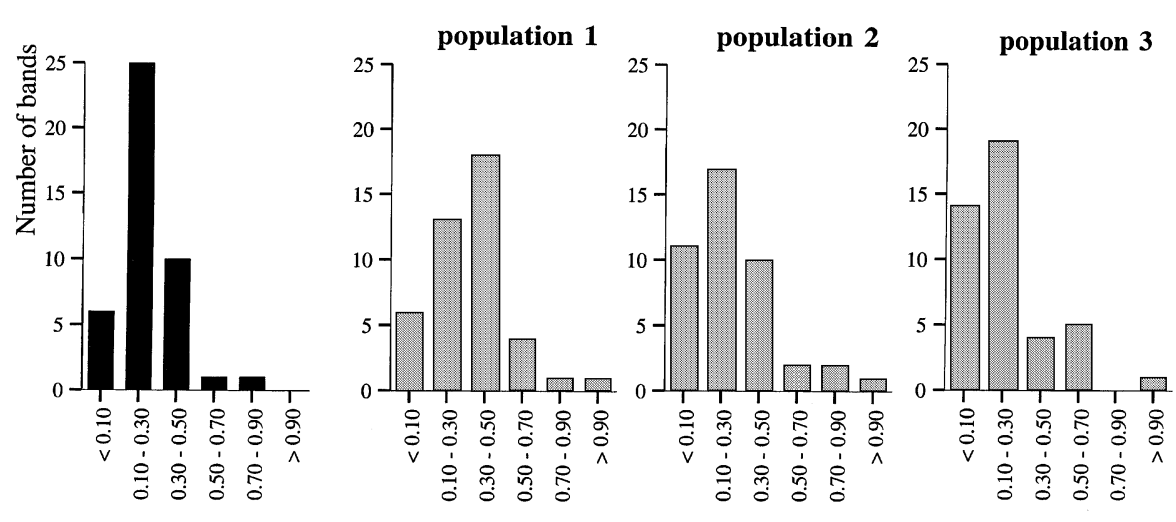

Frequency

Fig. 1 Number of bands observed as a function of their frequency for G. claroideum or Glomus DAOM 225952 and for each population.

To date, the reproduction pathway of AM fungi has been believed to be exclusively clonal (e.g. Rosendahl \& Taylor, 1997; Smith \& Read, 1997). If a population is an assemblage of clones - all members of a clone being connected to a common ancestor by purely asexual lineages - then the variability found within populations can be explained by mutation alone. In this case, differences observed between multilocus profiles are differences arising by mutation in spores descended from the ancestral clone. The populations could have been founded by genetically differentiated spores, that diverged a long time ago. As mutation is a constant process in time, these spores (or their clonal progenies) are still diverging. We thus may expect to find more and more haplotypes that are differentiated by few loci, whereas fewer and fewer haplotypes should be differentiated by many loci. The present results are not consistent with this hypothesis. A large number of differences between multilocus profiles pairwise com- parisons was observed for both species. Less than $5 \%$ of the comparisons differed by less than 5 fragments (3\%, $0.2 \%$ and $4.7 \%$ of the pairwise comparisons for population 1, 2, and 3 of Glomus DAOM 225952, and $1.1 \%, 2.8 \%$ and $0 \%$ of the pairwise comparisons for population 1, 2, and 3 of G. claroideum). By contrast, between $20 \%$ and $53 \%$ of the pairwise comparisons differed by more than 15 fragments. As a consequence, a second hypothesis to explain the high diversity observed would be the occurrence of recombination events. Linkage disequilibrium can arise in several ways, even in populations in which recombination is frequent, and it is thus difficult to know which evolutionary process(es) is implicated. Conversely, the random association of alleles between loci (linkage equilibrium) clearly indicates recombination within a population. For Glomus DAOM 225952, the proportion of linkage disequilibria varied between $53 \%$ and $39 \%(P<0.05)$, while $G$. claroideum exhibited between $61 \%$ and $48 \%$ of 
A

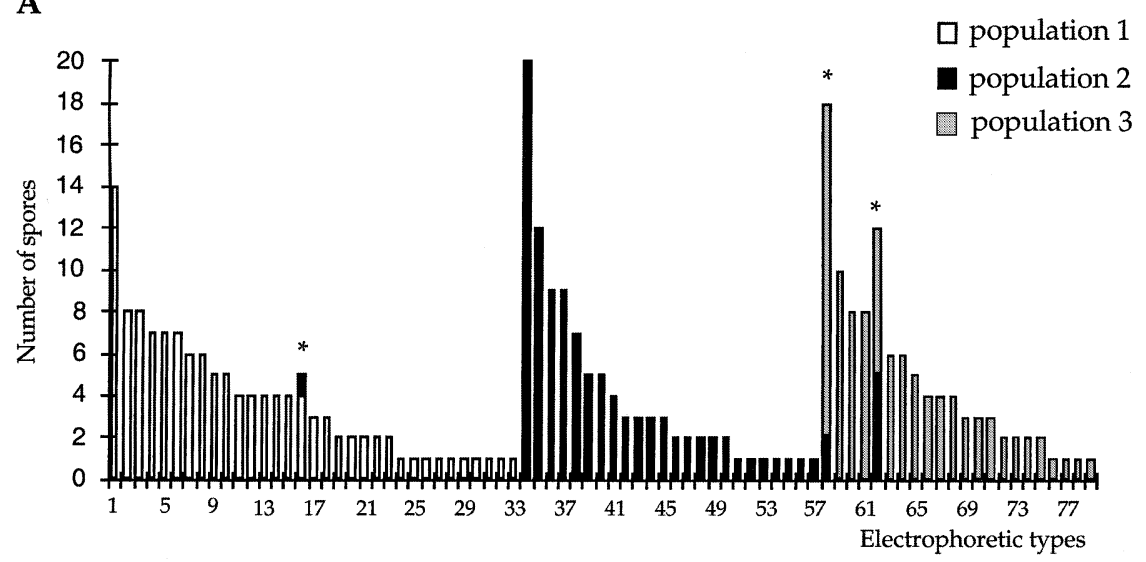

B
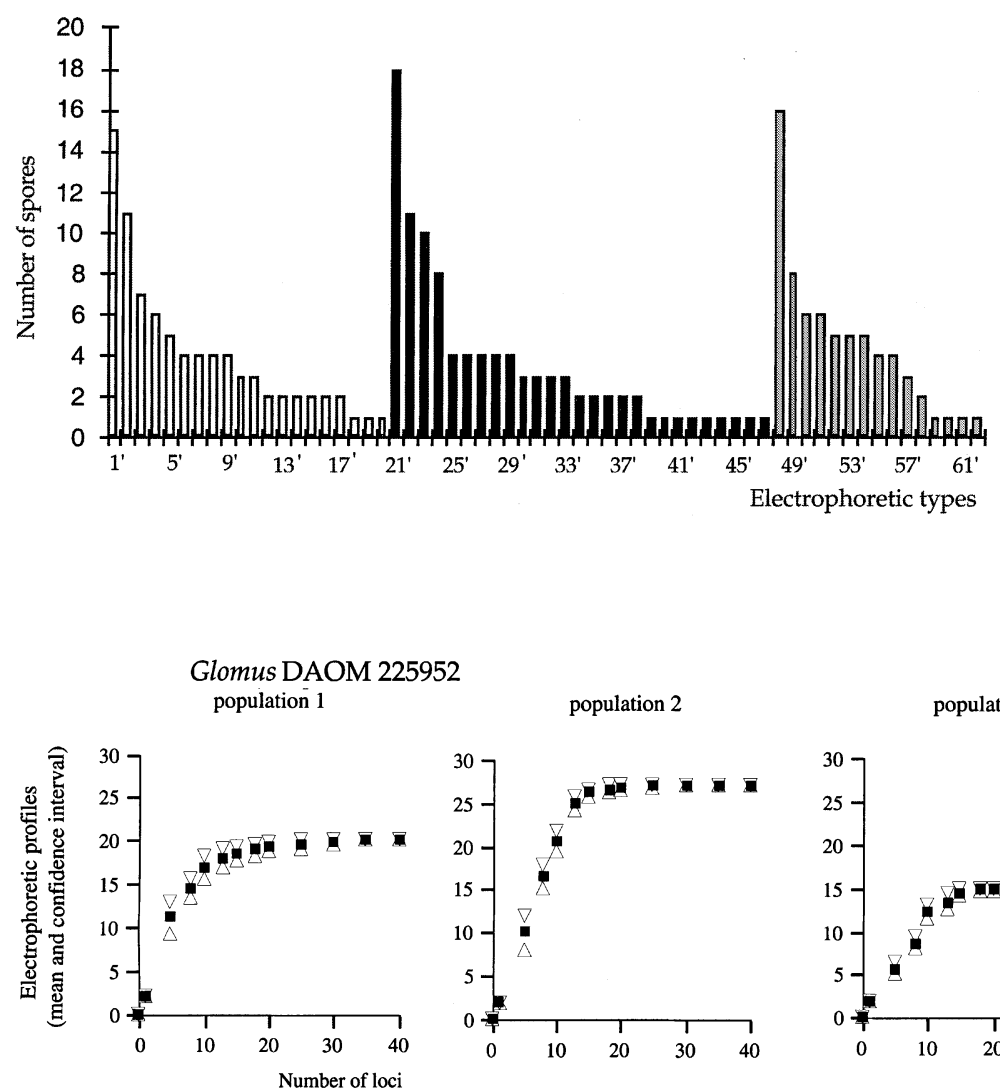

Glomus claroideum W2537 population 1

population 2

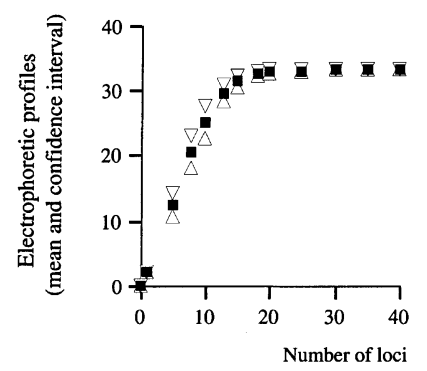

population 3

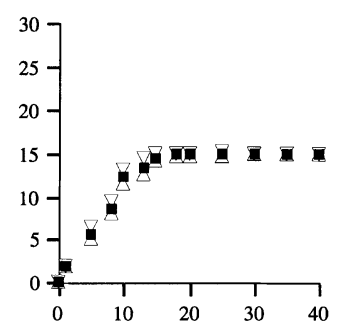

population 3

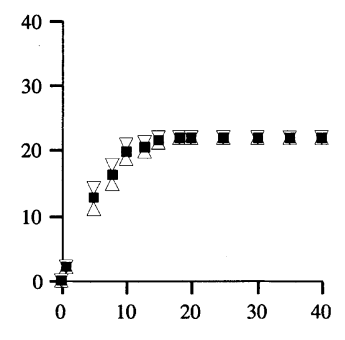

Fig. 2 Frequency of each electrophoretic types within each population of (a) G. claroideum and (b) Glomus DAOM 225952. Electrophoretic types common to two populations $(*)$.
Fig. 3 Resampling study: number of electrophoretic types (means and confidence intervals) observed in each population as a function of the number of loci.

(c) The Genetics Society of Great Britain, Heredity, 87, 243-253. 
Table 1 Population diversity of Glomus DAOM 225952 and G. claroideum

Table 2 Analyses of Molecular Variance (AMOVA) for the three populations of Glomus DAOM 225952 and $G$. claroideum

\begin{tabular}{|c|c|c|c|c|c|c|}
\hline \multirow[b]{2}{*}{ Population } & \multicolumn{3}{|c|}{ Glomus DAOM 225952} & \multicolumn{3}{|c|}{ G. claroideum } \\
\hline & 1 & 2 & 3 & 1 & 2 & 3 \\
\hline Number of spores & 81 & 98 & 68 & 123 & 108 & 99 \\
\hline $\begin{array}{l}\text { Number of different } \\
\text { electrophoretic profiles }\end{array}$ & 20 & 27 & 15 & 33 & 27 & 22 \\
\hline Number of polymorphic loci & 41 & 39 & 33 & 36 & 34 & 38 \\
\hline $\begin{array}{l}\text { Ratio: electrophoretic types } \\
\text { number/spore number }\end{array}$ & 0.25 & 0.28 & 0.22 & 0.27 & 0.25 & 0.22 \\
\hline
\end{tabular}

\begin{tabular}{lrrcrr}
\hline Source of variation & d.f. & SSD & $\begin{array}{c}\text { Variance } \\
\text { component }\end{array}$ & $\begin{array}{r}\% \text { total } \\
\text { variance }\end{array}$ & $P$-value* \\
\hline Glomus DAOM 225952 & & & & & \\
$\quad$ Among populations & 2 & 7.41 & 0.04 & 7.97 & $<0.001$ \\
$\quad$ Within populations & 244 & 112.37 & 0.46 & 92.03 & \\
$\begin{array}{l}\text { G. claroideum } \\
\quad \text { Among populations }\end{array}$ & 2 & 7.29 & 0.03 & 5.79 & $<0.001$ \\
Within populations & 327 & 154.11 & 0.47 & 94.21 & \\
\hline
\end{tabular}

*Nonparametric randomization test (1000 permutations).

Table 3 Percentages of linkage disequilibria significantly different from zero in the three populations of Glomus DAOM 225952 and G. claroideum

\begin{tabular}{|c|c|c|c|c|c|c|}
\hline & 1 & 1 & 2 & 2 & 3 & 3 \\
\hline Population & All spores & $\begin{array}{c}1 \text { Spore/ } \\
\text { multilocus } \\
\text { profile }\end{array}$ & All spores & $\begin{array}{l}\text { 1 Spore/ } \\
\text { multilocus } \\
\text { profile }\end{array}$ & All spores & $\begin{array}{l}1 \text { Spore/ } \\
\text { multilocus } \\
\text { profile }\end{array}$ \\
\hline G. DAOM 225952 & $\begin{array}{l}n=81 \\
41 \text { loci }\end{array}$ & $\begin{array}{l}n=20 \\
41 \text { loci }\end{array}$ & $\begin{array}{l}n=98 \\
39 \text { loci }\end{array}$ & $\begin{array}{l}n=27 \\
39 \text { loci }\end{array}$ & $\begin{array}{l}n=68 \\
33 \text { loci }\end{array}$ & $\begin{array}{l}n=15 \\
33 \text { loci }\end{array}$ \\
\hline Number of tests & 820 & 820 & 741 & 741 & 528 & 528 \\
\hline Fisher $(P<0.05)$ & $53 \%$ & $14 \%$ & $44 \%$ & $10 \%$ & $39 \%$ & $5 \%$ \\
\hline Bonferroni's sequential test & $19.5 \%$ & $7 \%$ & $16 \%$ & $4 \%$ & $14 \%$ & $0.4 \%$ \\
\hline G. claroideum & $\begin{array}{l}n=123 \\
36 \text { loci }\end{array}$ & $\begin{array}{l}n=33 \\
36 \text { loci }\end{array}$ & $\begin{array}{l}n=108 \\
34 \text { loci }\end{array}$ & $\begin{array}{l}n=27 \\
34 \text { loci }\end{array}$ & $\begin{array}{l}n=99 \\
38 \text { loci }\end{array}$ & $\begin{array}{l}n=22 \\
38 \text { loci }\end{array}$ \\
\hline Number of tests & 630 & 630 & 561 & 561 & 703 & 703 \\
\hline Fisher $(P<0.05)$ & $48 \%$ & $13 \%$ & $61 \%$ & $16 \%$ & $54 \%$ & $13 \%$ \\
\hline $\begin{array}{l}\text { Bonferroni's } \\
\text { Sequential test }\end{array}$ & $14 \%$ & $1.4 \%$ & $25 \%$ & $1.8 \%$ & $15 \%$ & $3.4 \%$ \\
\hline
\end{tabular}

$n$, number of individuals.

pairwise disequilibria $(P<0.05)$, depending on the population (Table 3). Removing putative clones strongly decreased these proportions: only $14 \%$ to $5 \%$ of significant linkage disequilibria $(P<0.05)$ were found for Glomus DAOM 225952 and $16 \%$ to $13 \%$ $(P<0.05)$ for G. claroideum (Table 3). Applying Bonferroni's sequential procedure reduced the proportions even more (Table 3 ). In a species that reproduces solely by recombination, linkage equilibrium among all the loci is expected. The present results showed that most of the loci are in linkage equilibria within the populations (between $84 \%$ and $95 \%$ of the pairwise comparisons). However, it cannot be concluded from these data that the genetic diversity is generated by recombination because a small part of the loci remains in linkage disequilibrium. So, the important issue is then to know if there is a recombination contribution to the genetic diversity in addition to clonality. One possible way to address this question is to compare the observed variance of similarities among multilocus profiles ( $I_{A}$ of Maynard-Smith et al., 1993) to the result to the $I_{A}$ computed from artificially recombined datasets (Burt

(C) The Genetics Society of Great Britain, Heredity, 87, 243-253. 
et al., 1996). At the species level, the $I_{A}$ fall well within the distribution of randomised datasets. For both Glomus DAOM 225952 and G. claroideum, 37 out of 300 calculated $I_{A}$ from the artificially recombined datasets were higher than the observed $I_{A}\left(I_{A}=0.253\right.$ and $I_{A}=0.162$, respectively) $(P=0.12)$, indicating no significant correlation of alleles across loci (Fig. 4). When populations were considered separately, recombination was found in each population isolated from the soil in plot 3: out of 300 artificially recombined datasets, $96(P=0.32)$ calculated $I_{A}$ showed a higher value than the observed $I_{A}\left(I_{A}=0.08\right)$ for Glomus DAOM 225952, while $61(P=0.20)$ were higher than the observed $I_{A}\left(I_{A}=0.165\right)$ for $G$. claroideum. In these populations, no significant correlation of 'alleles' across loci was observed (Fig. 4). For these populations, then, the present results strongly support the occurrence of recombination events. On the other hand, in population 1 of Glomus DAOM 225952 and G. claroideum, the observed $I_{A}$ reached the value of 0.800 and 0.571 , respectively. The computed $I_{A}$ from the recombined datasets shows no higher value than the observed $I_{A}$ for Glomus DAOM 225952 and two higher values for G. claroideum. For population 2, the observed $I_{A}$ for Glomus DAOM 225952 and G. claroideum were 0.405 and 0.975 , respectively, with 14 recombination $I_{A}$ showing higher values for Glomus DAOM 225952 $(P=0.05)$, and no higher recombination $I_{A}$ for G. claroideum. In contrast to the result for population 3 , the observed $I_{A}$ in populations 1 and 2 are significantly higher than the $I_{A}$ calculated from the artificially recombined datasets for the two fungal species. For these populations and despite the high linkage equilibrium proportion among loci the $I_{A}$ analyses do not confirm the occurrence of recombination events. Thus it can be concluded that the contribution of recombination to genetic diversity depends on the environment.

\section{Discussion}

The loss of genetic diversity is thought to reduce the ability of populations to adapt to changing environments (Fisher, 1930). The loss of AM fungal genetic diversity in soil is of great concern for soil protection because these fungi represent one of the most important groups of rhizospheric microorganisms, owing to their interactions with almost all natural plant communities and species (van der Heijden et al., 1998b). Until now, few published studies have focused on the genetic diversity of AM fungi. As far as we know, these studies were always performed on isolates maintained as pure cultures in laboratory conditions (e.g. Gadkar et al.,

\section{Glomus DAOM 225952}
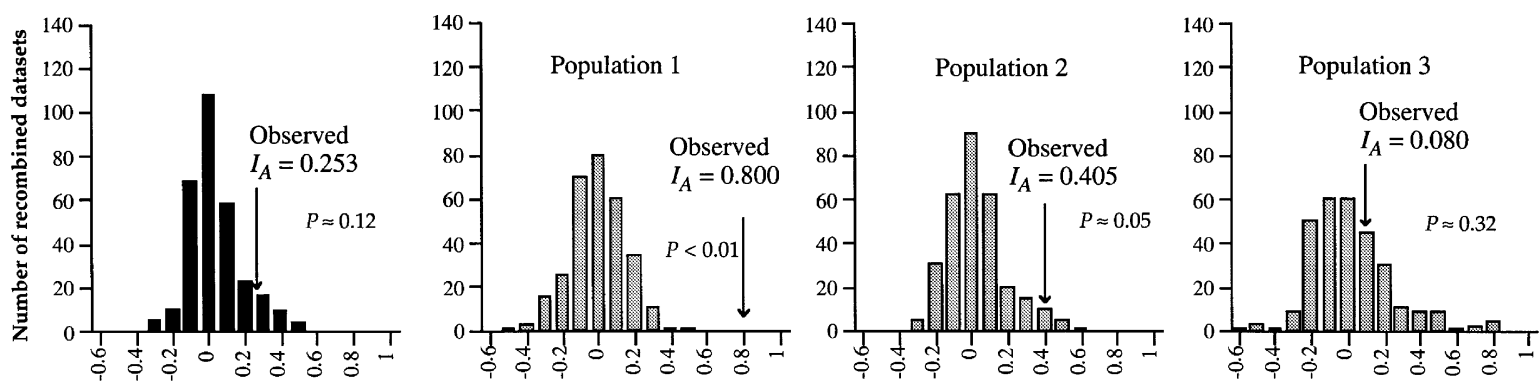

Index of Association

Glomus claroideum W2537
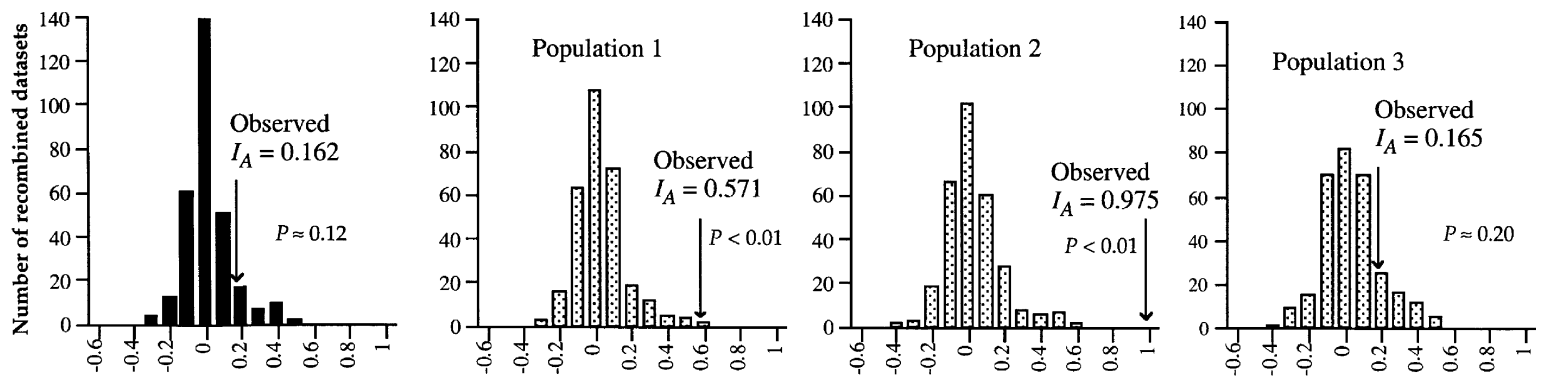

Index of Association

Fig. 4 Observed index of association (arrow) compared to indices of association computed from 300 artificially recombined datasets (randomization test) for G. claroideum or Glomus DAOM 225952 (black) and for the three populations of each species (grey). 
1997; Rosendahl \& Taylor, 1997; Zézé et al., 1997). This study is the first report focusing on the genetic diversity in natural populations of AM fungi sampled in different ecological conditions.

The genetic markers used (ISSR fingerprints) are as powerful as minisatellites or AFLP markers (Gadkar et al., 1997; Rosendahl \& Taylor, 1997; Zézé et al., 1997) in revealing differences among spores within species, and are thus a reliable technique for assessing genetic diversity in AM fungi. The resampling experiment described in Fig. 3 suggested that sample sizes of 39 and 43 markers were sufficient to describe population diversity of Glomus claroideum and Glomus DAOM 225952, respectively, in the three sampled plots.

The level of diversity observed in the natural AM fungi populations was unexpected, given the small numbers of spores found in the different soil samples (Vandenkoornhuyse, 1998). The number of polymorphic bands for the populations of G. claroideum and Glomus DAOM 225952 was higher than $80 \%$, and 15-33 different electrophoretic types were found depending on the population. These results were obtained using digestions of multilocus profiles to control for the homology of bands of identical mobility, but without complete sequencing. Nevertheless, in the worst case, if some patterns were identical by chance only, the level of diversity found would be an underestimate. For both species, an AMOVA analysis confirmed that within-population variability was higher within than that between populations. The low level of genetic differentiation among populations resulted from the high number of 'alleles' (multilocus profiles) considered at the species level ( 82 for G. claroideum and 62 for Glomus DAOM 225952). These results are inherent to the variance analysis method as pointed out by Nagylaki (1998), and Pannell \& Charlesworth (1999). $F_{\mathrm{ST}}$ may be a poor measure of population differentiation, because it can be particularly sensitive to the total genetic diversity across the species, irrespective of differentiation between demes. Low estimates of $F_{\mathrm{ST}}$ can be found when withindeme diversity is high, even if different demes have no alleles in common (Nagylaki, 1998). The low $F_{\mathrm{ST}}$ values among populations were statistically different from 0 $(P<0.001)$. Overall, only two multilocus profiles were common to two populations in G. claroideum (Fig. 2). The populations are thus genetically different for G. claroideum and for Glomus DAOM 225952, despite the very short distance between the sampled plots.

Mutation or recombination could have slowed the loss of genetic variation resulting from genetic drift and local selection in these populations. The present contribution suggests that mutation alone cannot explain the diversity found within populations. Most haplotypes differ by many bands, while a small number of differences should mostly be observed, owing to mutation. AM fungi are supposed to reproduce clonally and be asexual (e.g. Rosendahl \& Taylor, 1997; Smith \& Read, 1997; p. 16) because there is no evidence for the occurrence of nuclear fusion and meiosis (Biancotto \& Bonfante, 1993). However, in a recent study, the possible exchanges of nuclei via anastomosis was shown (Giovannetti et al., 1999). By using 17 and 13 polymorphic AFLP markers in Glomus caledonium and Glomus mosseae, respectively, Rosendahl \& Taylor (1997) found no evidence for recombination when calculating the association index of Maynard Smith et al. (1993). Conversely, in the present study, the statistical tests for recombination (linkage disequilibria and association indices) showed that the reproductive mode of G. claroideum and Glomus DAOM 225952 cannot be exclusively clonal.

In populations displaying recombination, a decrease of the proportion of significant linkage disequilibria within population is expected when putative clones are removed from the dataset. For example, Milgroom et al. (1992), by using DNA fingerprints on the fungus Cryphonectria parasitica, showed that $11 \%$ of linkage disequilibria were significant $(P<0.05)$ when putative clones were not deleted, and $7.5 \%(P<0.05)$ when using one representative of each genotype (Fisher's exact test). The authors concluded from these low values of linkage disequilibria that recombination events occurred in this fungus. In the present study, only $5 \%$ to $16 \%$ of linkage disequilibria were significant at $P<0.05$ when putative clones were excluded from the analysis $(0.4 \%$ to $7 \%$ at $P<0.001$ applying Bonferroni's sequential test). These results led to the hypothesis that part of the diversity observed in some populations of the two AM fungi species was generated by recombination or recombination-like phenomenon. This hypothesis was reinforced by the analyses of indices of association, which showed that recombination cannot be excluded in populations 3 of $G$. claroideum and Glomus DAOM 225952 (Fig. 4). In accordance with Maynard Smith et al. (1993), we hypothesize that the population structure is 'epidemic' ([...] frequent recombination within members of the population [...] and occasionally a highly successful individual arises and increases rapidly to produce an epidemic clone).

Different mechanisms may explain the occurrence of recombination in the coenocytes AM fungi: sexuality involving genetic reassortments between nuclei within spore or parasexuality involving, for example (i) homologous recombinations in highly repeated DNA seqquences, as previously suggested by Zézé et al. (1996) for Scutellospora castanea, or (ii) nuclei exchange by hyphal anastomosis (Giovannetti et al., 1999). Amastomoses have been observed by confocal microscope of stained hyphae (sulforhodamine G) of Glomus DAOM 225952 and occurred at a high frequency 
(Vandenkoornhuyse, Tonin \& Mustin, unpubl. results, pictures available upon request).

These recombination events seemed to have occurred mainly in population 3 of both species. Conversely, in populations 1 and 2, recombination events were not confirmed by the computation of the Indices of Association (Fig. 4). The incorporation of sewage sludge in this long-term field experiment has led to a significant increase of total and available concentrations of heavy metals in the rhizospheric soil (Knight et al., 1998). The metal concentrations are six- to eight-fold higher in the soil of plot 3 compared to plot 1 and two- to three-fold higher compared to those in plot 2 (Knight et al., 1998; Zhang et al., 1998). The sewage sludge amendment also modified the organic carbon content $(0.9 \%$ for the soil $1,1.1 \%$ for the soil 2 and $1.5 \%$ for the soil 3 ) and the $\mathrm{pH}$ of the soil (7.1 for the soil 1, 6.8 for the soil 2 and 6.1 for the soil 3) (Knight et al., 1998). The environmental constraints in soil 3 may have led to an enhancement of recombination phenomena for both species. This mechanism might allow the fungi to generate more genetic diversity in a perturbed environment, and to select more rapidly adapted genotypes, which leads to the appearance of an 'epidemic' population structure. This hypothesis could have important consequences on the ecology of the association with the host plant, because AM fungi can confer to their host plant a passive 'tolerance' to a number of environmental stresses (Smith $\&$ Read, 1997). One of the major functions of mycorrhiza is to allow the adjustment to local soil conditions and the acclimation of plants (Wilkinson, 1995). Owing to recombination, there are more opportunities for the occurrence of genetic combination adapted to the environment heterogeneity in these AM fungi. This, in turn, could help the passive adaptation of mutualistic higher plants (Wilkinson, 1995). Nevertheless, other soil characteristics might be responsible of the observed results such as, for example, the soil microorganisms. These microorganisms are likely to interact with AM fungi in different ways (e.g. parasitism), which can lead to different population genetic structures.

Further investigations are needed to confirm the results presented herein. It would be interesting to make the same population analysis using soil samples from different plots of the same treatment. Future studies may focus on the temporal dynamics of genetic variability in the populations of AM fungi in order to understand better the mechanisms of asexual, sexual and/or parasexual reproduction.

\section{Acknowledgements}

We would like to thank Marie-Hélène Martel and Thidar Myint for technical assistance. The authors are very grateful to Austin Burt for sending his program 'haplo3.exe' and to Isabelle Olivieri, Frédérique Viard, Myriam Valero, J. Peter, W. Young and Thorunn Helgason for comments on the manuscript. This research was supported by a grant from the European Community (EV5V-CT94-0415).

\section{References}

ANDERSON, J. B., KOHN, L. M. AND LESLIE, J. F. 1992. Genetic mechanisms in fungal adaptation. In: Carroll, G. C. and Wicklow, D. T. (eds) The Fungal Community: its Organization and Role in Ecosystem, pp. 73-98. Dekker, New York.

BIANCOTTO, V. AND BONFANTE, P. 1993. Evidence of DNA replication in an arbuscular mycorrhizal fungus in the absence of the host plant. Protoplasma, 176, 100-105.

BONNIN, I., HUGUET, T., GHERARDI, M., PROSPERI, J. M. AND OLIVIERI, I. 1996. High level of polymorphism and spacial structure in a selfing plant species, Medicago truncata (Leguminosae), shown using RAPD markers. Am. J. Bot., 83, 843-855.

BROWN, J. K. M. AND WOLFE, M. S. 1990. Structure and evolution of a population of Erisiphe graminis f. sp. hordei. Plant Pathol., 39, 376-390.

BURDON, J. J. AND ROELFS, A. P. 1985. The effect of sexual and asexual reproduction on the isozyme structure of populations of Puccinia graminis. Phytopathology, 75, 1068-1073.

BURT, A., CARTER, D. A., KOENIG, G. L., WHITE, T. J. AND TAYLOR, J. w. 1996. Molecular markers reveal cryptic sex in human pathogen Coccidioides immitis. Proc. Natl. Acad. Sci. U.S.A., 93, 770-773.

BUSCOT, F., WIPF, D., DI BATTISTA, C., MUNCH, J. C., BOTTON, B. AND MARTIN, F. 1996. DNA polymorphism in morels: PCR/ RFLP analysis of the ribosomal DNA spacers and microsatellite-primed PCR. Mycol. Res., 100, 63-71.

BUTLIN, R. K., SCHÖN, I. AND MARTENS, K. 1999. Origin, age and diversity of clones. J. Evol. Biol., 12, 1020-1022.

CHEN, R.-S. AND MCDONALD, B. A. 1996. Sexual reproduction plays a major role in the genetic structure of populations of the fungus Mycosphaerella graminicola. Genetics, 142, 1119-1127.

ESSELMAN, E. J., JIANQIANG, L., CRAWFORD, D. J., WINDUS, J. L. AND WOlfE, A. D. 1999. Clonal diversity in the rare Calamagrostis porteri ssp. insperata (Poaceae): comparative results for allozymes and random amplified polymorphic DNA (RAPD) and intersimple sequence repeat (ISSR) markers. Mol. Ecol., 8, 443-451.

EXCOFFIER, L., SMOUSE, P. E. AND QuATTRo, J. M. 1992. Analysis of molecular variance infered from metric distances among DNA haplotypes: application to human mitochondrial DNA restriction data. Genetics, 131, 479-491.

FISHER, R. A. 1930. The Genetical Theory of Natural Selection. Oxford University Press, Oxford.

GADKAR, V., ADHOlEyA, A. AND SATYANARAYANA, A. 1997. Randomly amplified polymorphic DNA using the M13 core sequence of the vesicular-arbuscular mycorrhizal fungi Gigaspora margarita and Gigaspora gigantea. Can. J. Microbiol., 43, 795-798.

(c) The Genetics Society of Great Britain, Heredity, 87, 243-253. 
GILler, K. E., BEARE, M. H., LAVELle, P., IZAK, A. M. N. AND SwIFT, M. J. 1997. Agricultural intensification, soil biodiversity and agroecosystem function. Appl. Soil Ecol., 6, 3-16.

GIOVANNETTI, M., AZZOlini, D. AND CITERNeSI, A. S. 1999. Anastomosis formation and nuclear and protoplasmic exchange in Arbuscular Mycorrhizal fungi. Appl. Env. Microbiol., 65, 5571-5575.

HOLM, s. 1979. A simple sequencial rejective multiple test procedure. Scand. J. Stat., 6, 65-70.

hOSNY, M., HiJRI, M., PASSERIEUX, E. AND DUlieU, H. 1999. rDNA units are highly polymorphic in Scutellospora castanea (Glomales, Zygomycetes). Gene, 226, 61-71.

KNIGHT, B. P., CHAUDRI, A. M., MCGRATH, S. P. AND GILLER, K. E. 1998. Determination of chemical availability of cadmium and zinc in soils using inert soil moisture samplers. Env. Pol., 99, 293-298.

KOHLI, Y., BRUNNER, L. J., YOELL, H., MILGROOM, M. G., ANDERSON, J. B., MORRALL, R. A. A. ET AL. 1995. Clonal dispersal and spatial mixing in populations of the plant pathogenic fungus, Sclerotinia sclerotiorum. Mol. Ecol., 4, 69-77.

LANFRANCO, L., DELPERO, M. AND BONFANTE, P. 1999. Intrasporal variability of ribosomal sequences in the endomycorrhizal fungus Gigaspora margarita. Mol. Ecol., 8, 37-45.

MAYNARD SMITH, J., SMITH, N. H., O'ROURKE, M. AND SPRATT, B. G. 1993. How clonal are bacteria? Proc. Natl. Acad. Sci. U.S.A., 90, 4384-4388.

MILGROOM, M. G., LIPARI, S. E. AND POWELL, W. A. 1992. DNA fingerprinting and analysis of population structure in the Chestnut Blight fungus, Cryphonectria parasitica. Genetics, 131, 297-306.

MORTON, J. B. AND BENNY, G. L. 1990. Revised classification of arbuscular mycorrhizal fungi (Zygomycetes): a new order, Glomales, two new suborders, Glomineae and Gigasporineae, and two new families, Acaulosporaceae and Gigasporaceae, with an emendation of Glomaceae. Mycotaxon, 37, 471-491.

NAGAOKA, T. AND OGIHARA, Y. 1997. Applicability of intersimple sequence repeat polymorphisms in wheat for use as DNA marker in comparison to RFLP and RAPD markers. Theor. Appl. Gen., 94, 597-602.

NAGYLAKI, T. 1998. Fixation indices on subdivided populations. Genetics, 148, 1325-1332.

NÜRnBerger, B. AND GABRIEL, w. 1999. Continued hope for a general explanation of sex. J. Evol. Biol., 12, 1040-1042.

PANNELl, J. R. AND CHARLESWORTH, B. 1999. Neutral genetic diversity in a metapopulation with recurrent local extinction and recolonisation. Evolution, 53, 664-676.

PEET, R. 1974. The measurement of species diversity. Ann. Rev. Ecol. Syst., 5, 285-307.

PIELOU, E. C. 1969. An Introduction to Mathematical Ecology. Wiley, New York.

PIROZYNSKI, K. A. AND MALLOCH, J. G. 1975. The origin of land plants: a matter of mycotrophism. Biosystems, 6, 153-164.

RAYMOND, M. AND ROUSSET, F. 1995. GENEPOP (Version 1.2), a population genetics software for exact tests and ecumenicism. J. Hered., 86, 248-249.

RICE, W. R. 1989. Analysing tables of statistical test. Evolution, 43, 223-225.

ROSENDAHL, S. AND TAYLOR, J. W. 1997. Development of multiple genetic markers for studies of genetic variation in arbuscular mycorrhizal fungi using AFLP. Mol. Ecol., 6, 821-829.

SELOSSE, M. A. AND LE TACON, F. 1998. The land flora: a phototroph-fungus partnership? Trends Ecol. Evol., 13, 15-19.

SMITH, S. E. AND READ, D. J. 1997. Mycorrhizal Symbiosis, 2nd edn. Academic Press, London.

SOKAL, R. R. AND ROHLF, F. J. 1995. Biometry: the Principles and Practice of Statistics in Biological Research, 3rd edn. Freeman, New York.

STREITWOLF-ENGEL, R., BOLLER, T., WIEMKEN, A. AND SANDERS, I. R. 1997. Clonal growth traits of two Prunella species are determined by co-occurring arbuscular mycorrhizal fungi from a calcareous grassland. J. Ecol., 85, 181-191.

VANDENKOORNHUYSE, P. 1998. Approche de la diversité inter-et intraspécifique des champignons mycorhiziens à arbuscules. Ph.D. Thesis, University of Nancy.

VANDENKOORNHUYSE, P. AND LEYVAL, C. 1998. SSU rDNA sequencing and PCR-fingerprinting reveal genetic variation within Glomus mosseae. Mycologia, 90, 792-798.

VAN DER HEIJDEN, M. G. A., BOLLER, T., WIEMKEN, A. AND SANDERS, I. R. 1998a. Different arbuscular mycorrhizal fungal species are potential determinants of plant community structure. Ecology, 79, 2082-2091.

VAN DER HEIJDEN, M. G. A., KLIRONOMOS, J. N., URSIC, M., MOUTOGLIS, P., STREITWOLF-ENGEL, R., BOLLER, T. ET AL. 1998b. Mycorrhizal fungal diversity determines plant biodiversity, ecosystem variability and productivity. Nature, 396, 69-72.

WeIR, B. S. 1990. Genetic Data Analysis. Sinauer Publications, Sunderland, MA.

WEIR, B. S. AND COCKERHAM, C. C. 1984. Estimating F-statistics for the analysis of population structure. Evolution, 38, 1358-1370.

WEST, S. A., LIVELY, C. M. AND READ, A. F. 1999. A pluralistic approach to sex and recombination. J. Evol. Biol., 12, 1003-1012.

WILKINSON, D. M. 1995. Metal resistance in trees: the role of mycorrhizae. Oikos, 72, 298-299.

ZÉZÉ, A., HOSNY, M., GIANINAZZI-PEARSON, V. AND DULIEU, H. 1996. Characterization of a highly repeated DNA sequence (SC1) from the arbuscular mycorrhizal fungus Scutellospora castanea and its detection in planta. Appl. Env. Microbiol., 62, 2443-2448.

ZÉZÉ, A., SULISTYOWATI, E., OPHEL-KELLER, K., BARKER, S. AND SMITH, S. 1997. Intersporal genetic variation of Gigaspora margarita, a vesicular arbuscular mycorrhizal fungus, revealed by M13 minisatellite-primed PCR. Appl. Env. Microbiol., 63, 676-678.

ZHANG, H., DAVISON, W., KNIGHT, B.P. AND MCGRATH, S. P. 1998. In situ measurement of solution concentrations and fluxes of trace metals in soils using DGT. Envir. Sci. Tech., 32, 704-710.

ZHOU, Z., MIWA, M. AND HOGETSU, T. 1999. Analysis of genetic structure of a Suillus grevillei population in a Larix kaempferi stand by polymorphism of inter-simple sequence repeat (ISSR). New Phytol., 144, 55-63.

ZIETKIEWICZ, E., RAFALSKI, A. AND LABUDA, D. 1994. Genome fingerprinting by simple sequence repeat (SSR)-anchored polymerase chain reaction amplification. Genome, 20, 176-183. 